\title{
Problem of Multiflow with Application in the Road Transportation Network Exploited by Transco Company in Kinshasa City
}

\author{
${ }^{1}$ Fernand MAMANYA TAPASA, ${ }^{2}$ Rostin MABELA MAKENGO MATENDO \\ ${ }^{1}$ Faculty of Science /Department of Mathematics and Computer Science / \\ National Pedagogical University (UPN), Democratic Republic of Congo (DRC), \\ ${ }^{2}$ Faculty of Science /Department of Mathematics and Computer Science /Division \\ University of Kinshasa, Democratic Republic of Congo (DRC),
}

\begin{abstract}
*Corresponding Author: Fernand MAMANYA TAPASA, Faculty of Science /Department of Mathematics and Computer Science /National Pedagogical University (UPN), Democratic Republic of Congo (DRC),
\end{abstract}

\begin{abstract}
This article deals with the problem of maximal multiflow and applies it on the Kinshasa city transportation network exploited by the transport company called "Transco". It aims to determine additional equipment which permits the company to accomplish itself the trafic in the actual network. The two kinds of buses used by this company have been selected in the study as the two types of products moving in the system. The capacity of a one-way road (500 vehicles per hour) has been taken as the maximal capacity of each road band. The linear program obtained is solved by means of the "Linear Program Solver" software and the results show that the company covers now about $1.25 \%$ of the flow in the network. Thus, we end the study showing additional equipment which allows the company to assure itself the transport in the network.
\end{abstract}

Keywords: Fuzzy multiflow, types of products, standard capacity, linear program solver, Transco Company

\section{INTRODUCTION}

The problem of multiflow concerns the transportation in a network in which various types of products must be transported from their sources to specific destinations. Each road has some transportation capacity, and there are inquiries (demands) associated with each pair of source-destination. The network that connects sources to destinations may be modeled by the theory of graphs like a transportation network. The multiflow problem is a generalization of the flow problem which deals with the case of one type of product, one source and one destination.

In the literature, there are plenty of problems dealing with the flow in transportation network (see e.g. Harris and Ross [6]; Ford and Fulkerson [5]; Edmonds and Karp[4]). But only a few works among them such as Bentz [1]; Karima [7]; Costa [2], Mamanya[10] and Renfrey [11] have been devoted to the multiflow problem. In these both problems, the practical and theoretical interest were to provide answers to some questions in numerous industrial applications, namely in the design and processing of telecommunication, road transportation network, etc.

In the present article, we show how to apply the multiflow theory to the system transportation in Kinshasa city. The essential contribution of this article consists in modeling and solving the problem of multiflow in a concret case of Kinshasa city transportation. Through the maximum multiflow calculation, our aim pursued is split into three questions:

- What proportion of the flow Transco covers nowadays comparatively to the maximal flow in the network?

- What additional equipment (number of vehicles) this company needs to assure the maximal flow in the actual configuration network by itself?

- Among this equipment, what is the minimum quantity of each type of vehicle must be provided? 
This article is organized as follows: Section 2 recalls the multiflow problem theory. Section 3 states the system of road transportation exploited by Transco Company in Kinshasa city. Section 4 presents the road network of Transco Company and its graph. Section 5 gives the modeling and the solution of the problem. Section 6 presents the results and discussion and Section 7 puts a conclusion.

\section{Statement Of The Problem Of Multiflow}

Let $\mathrm{G}=(\mathrm{P}, \mathrm{A}, \mathrm{C}, \mathrm{X})$ be an oriented or non valued graph where $\mathrm{P}$ is a set of $\mathrm{n}$ nodes, $\mathrm{A}$ is a set of $\mathrm{m}$ edges (or arcs) and $C$ a set of capacities noted cij(i,j adjacent). $X=\{x i j \mid i, j \in G\}$ is a set of flows of goods moving in $\mathrm{G}$. To each edge is associated a capacity cij which describes the upper bound of the flow on this edge ; $x i j \leq$ cij. To each edge is associated equally an unit cost $\delta \mathrm{ij}$ which describes the cost per unit of flow on this edge. Let L be a list of pairs (sources si, destinations (sinks) pi) of the nodes in $\mathrm{G}$ (with si $6=$ pi, $\forall \mathrm{i}$ ). These pairs are called links; si and pi are called terminals. $\mathrm{G}$ is called support graph. Let us consider the flow for $\mathrm{k}$ types of distinct products between pairs of sourcesdestinations $(\mathrm{k}=1,2, \ldots, \mathrm{K})$. On each edge aij $\in \mathrm{A}(\mathrm{i}, \mathrm{j}$ adjacent $)$, such a flow is often note $\mathrm{d}^{x_{i j}^{(k)}}$.

On each path source - destination having q nodes $(\mathrm{si}, \ldots, \mathrm{pi})=(1,2, \ldots, \mathrm{q})$, the flow of one product of type $\mathrm{k}$ moving on the path, note $\mathrm{d} X_{s_{i} p_{i}}^{(k)}$, is calculated by :

$$
x_{i j}^{(k)}=\sum_{i=1}^{n} \sum_{j=1}^{n} C_{i j}^{(k)} \quad \quad(k \text { constant })
$$

According to? [], using all $\mathrm{k}$ types of products, the multiflow of the entire network noted $X_{G}^{(k)}$ is given by the following formula:

$$
x_{G}^{(k)}=\sum_{k=1}^{K} \sum_{\substack{i=1 \\ j=1}}^{n} C_{i j}^{(k)} n
$$

under constraints (Mamanya [9]:

$$
\left\{\begin{array}{l}
\sum_{k=1}^{K} x_{i . j}^{(k)} \leq C i j, \quad i=1, \ldots, n, j=1, \ldots, n \text { et } k=1, \ldots, K \\
\sum_{k) 1}^{K} x_{i . j}^{(k)}=X i=X j=\sum_{k}^{K} x_{j . i}^{(k)}, i=\text { source et } j=\text { destination } \\
\sum_{k) 1}^{K} x_{i . j}^{(k)}-\sum_{k=1}^{(K)} x_{j . i}^{(k)}=0, i \neq \text { sources } \text { et } j \neq \text { destination } \\
x_{i . j}^{(k)} \in N
\end{array}\right.
$$

\section{SYSTEM OF ROAD TRANSPORTATION}

There exist two types of roads (Délephanque [3]):

- Road with continuous flow: it is essentially about the type of road on which traffic is uninterrupted. Its flow is regular.

- Road with discontinuous flow: it is about a type of road on which traffic is broken. Its flow is irregular.

Note: the capacity of a road is the hourly flow of vehicles, goods or individuals that it can support in a given period of time. That value is a function of three concepts ([8], [10]):

- Road conditions: these are the characteristics of a road, such as its type, the number of ways or bands, the width of ways, and the expected circulation speed.

- Traffic conditions: characteristics of control structure as well as road regulations like speed limit, one-way road, and rules of priority. 
Problem of Multiflow with Application in the Road Transportation Network Exploited by Transco Company in Kinshasa City

Thus, according to that precedes, the standard capacity of a road is nearly 1000 vehicles per hour for roads with continuous flow having two ways, and nearly 500 for roads with discontinuous flow having one single way.

In this article, the road capacity per hour is considered as the number of ways that it has, multiplied by 500. Traffic can be approached from three elementary measurements: speed, volume, and density.

Speed relates to the distance run per time unit. Average speed is the parameter the most used.

\section{Presentation of Transco Company}

\subsection{Historical background [11]}

Everything started from a strike by the cooperation of (professionals of transportation) of private transporters of Kinshasa city launched in April 2012). In front of that disaster which paralyzed the city of Kinshasa and, exhausted by the permanent difficulty of the Congolese population to move decently, the central government opted to act. So, during the council of Ministers held in June 2012, it was decided to buy new buses and entrust their management to a new company. It is, then, in this context, that the "Transportation in the Congo", TRANSCO in short, arose in January 2013 on a decree by the prime Minister in order to meet the needs for the mobility of the Congolese population. The government of RDC appealed to the expertise of the "Régime Autonomies des transports Parisiens-international, RATP-I. So, in April 2013, a contract of technical assistance was signed between the Congolese government and the RATP-I. And, dewing 15 months, TRANSCO worked with the RATO-I until October 2015, when a new committee took over the management of the company. TRANSCO is a public Congolese establishment specialized in the field of urban and interurban transportation. Its head office is based in Kinshasa. Supported by 2,687 men and women, it has an annual turnover of CDF 23995057 556.29. The main jobs there are: regulators, drivers, collectors, controllers, technicians, and mechanizes. The vehicle stock consists of 499 buses among which 369 standard buses and 130 mini-buses. Those buses transport an annual average of 44648375 passengers, be them a monthly average of 3720698 passengers, and a daily average of 200000 passengers. TRANSCO offers services of school bus subscription and bus renting. It also exploits a Kinshasa-Kikwit inter-urban transportation network, with the project to cover the town of Matadi very soon. Its urban network includes 28 lines shared throughout the network of Kinshasa city below.

\subsection{Network graph exploited by Transco}

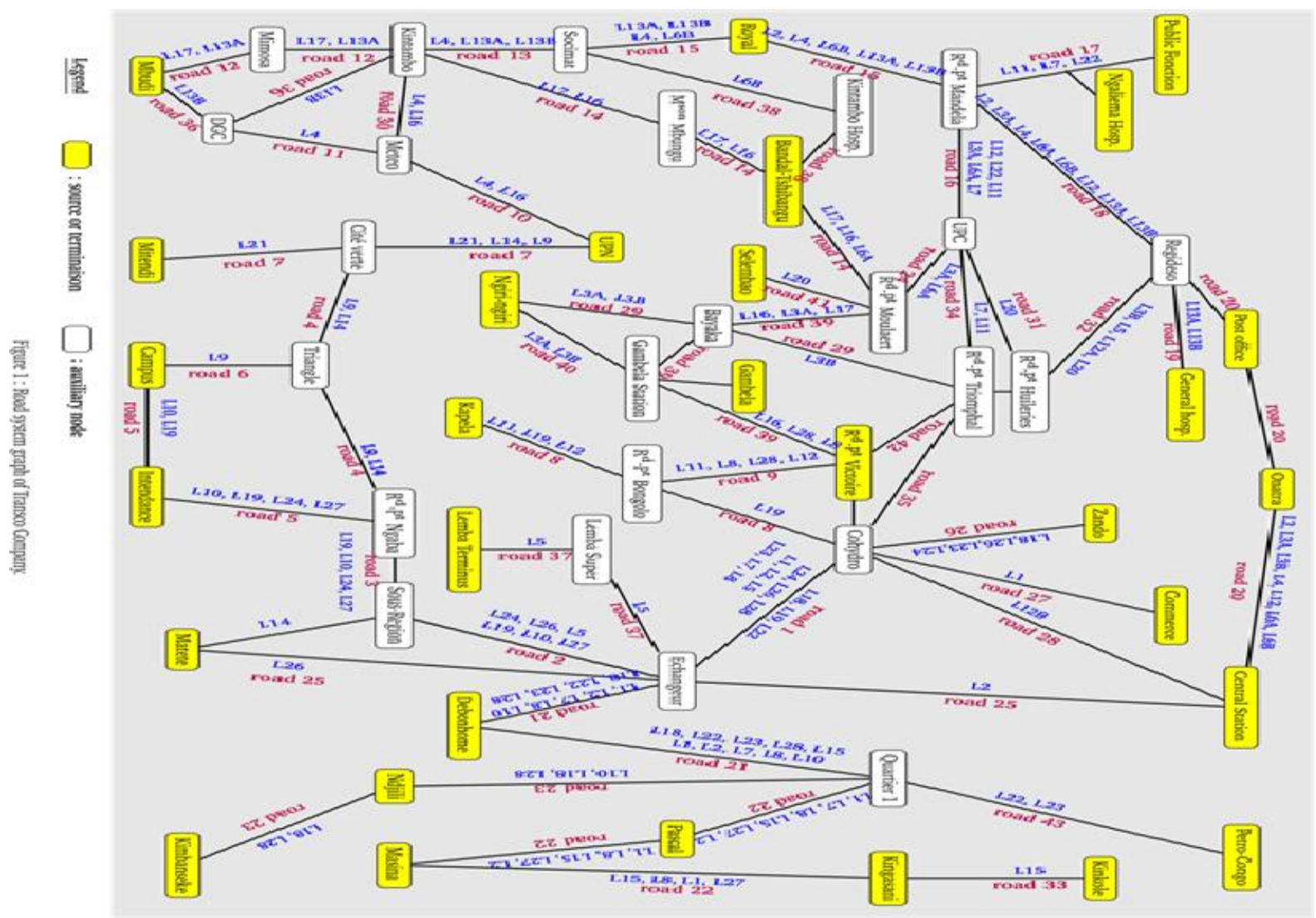

International Journal of Scientific and Innovative Mathematical Research (IJSIMR) 
Problem of Multiflow with Application in the Road Transportation Network Exploited by Transco Company in Kinshasa City

\section{MODELING}

The conformity to the multiflow network theory requires to provide the following steps:

- To set the way of circulation on each line (arc) and for each type of product. In our model, the way of circulation goes from the source to the terminus (destinations). However, the terminus may become a source, and a source may become a terminus. That compels us to consider a nonoriented network.

- To fix per hour the capacity of each road; this parameter is often considered as the maximal number of products observed registered in a fixed point of the network. For lack of standard capacity that must have a raad, we consider 500 vehicles by band and by hour([10)].

To determine the different types of products transported from their sources to their destinations. The following table 1 shows how the two types of Tranco products (standard buses and minibuses) are distributed in the network lines. Let us note that L25 is not working yet, and L14 and L9 are temporarily stopped.

Table 1. Distribution of products on the lines

\begin{tabular}{|l|l|l|l|l|l|l|l|l|l|l|l|}
\hline \multicolumn{4}{|l|}{ Product of type 1 (Standard buses) } & \multicolumn{4}{|c|}{ Product of type 2 (Mini-buses ) } \\
\hline L1 & L2 & L4 & L5 & L7 & L8 & L9 & L3A & L3B & L6A & L6B & L11 \\
\hline L10 & L13A & L13B & L14 & L15 & L16 & L17 & L 12A & L21 & L22 & L23 & L26 \\
\hline L18 & L19 & L20 & L24 & L27 & L28 & & L12B & & & & \\
\hline
\end{tabular}

- Consider the flow as the amount of goods that effectively pass on a roadway during this specific moment of time. In this article, we consider as flow upon entry, the number of buses that Transco sends on each line as indicated on the table 2.

- To merge into one single edge ( $\operatorname{arc})$ different roads having a same source and the same terminus, by summation of their respective capacities. In our analysis, L3A and L3B, L6A and L6B, L12A and L12B as well as L13A and L13B have been merged respectively into L3, L6, L12, L13.

To assure the transport in the network, Transco has at one's disposal 499 buses among which 390 standards buses and 90 mini-buses turn effectively on about 32 lines as indicated on the table 2.

Table 2. Transco network lines

\begin{tabular}{|c|c|c|c|c|c|}
\hline LINE & DEPARTURE & TERMINUS & LINE & DEPARTURE & TERMINUS \\
\hline L1 & Kingasani & - Commerce & L13B & Mbudi & - Gen. Hosp. via DGC \\
\hline $\mathrm{L} 2$ & Masina & - Royal & L14 & Matete & - UPN \\
\hline L3A & Ngiri-ngiri & - Central Station via 24 Nov. & L15 & Kinkole & - Debonhome \\
\hline L3B & Ngiri-ngiri & - Central Station via Huileries & L16 & UPN & - Victoire \\
\hline L4 & UPN & - Central Station & L17 & Mbudi & - Gambela \\
\hline L5 & Lemba & - Post Office & L18 & Kimbaseke & - Zando \\
\hline L6A & Bandal-Tshibangu & - Onatra via Molaert & L19 & Campus & - Victoire \\
\hline L6B & Bandal-Tshibangu & - Onatra via Kintambo Hosp. & L20 & Selembao & - Zando \\
\hline L7 & Pascal & - Public Fonction & L21 & Mitendi & - UPN \\
\hline L8 & Kingasani & - Gambela & L22 & Petro-congo & - Public Fonction \\
\hline L9 & UPN & - Campus & L23 & Petro-congo & - Zando \\
\hline L10 & Ndjili & - Campus & L24 & Intendance & - Zando \\
\hline L11 & Kapela & - Ngaliema Hospital & $\mathrm{L} 25$ & & Non-operational \\
\hline L12A & Kapela & - Central Station via Huileries & L26 & Matete & - Zando \\
\hline L12B & Kapela & - Central Station via Kasaï & L27 & Kingasani & - Intendance \\
\hline L13A & Mbudi & - Gen. Hosp. via Tourisme & L28 & Kimbaseke & - Gambela \\
\hline
\end{tabular}

As for distribution of flows in the network, we have splintered the network into 43 roads as indicated on the table 3. 
Problem of Multiflow with Application in the Road Transportation Network Exploited by Transco Company in Kinshasa City

Table 3. Routes du réseau exploité par Transco.

\begin{tabular}{|c|c|c|c|}
\hline $\mathbf{N} \circ$ & ROUTE & LIGNES & CAPACITES DES ROUTES \\
\hline 1 & Échangeur - Cohydro & $\begin{array}{l}\text { L1, L2, L5, L7, L8, L18, L19, L22, } \\
\text { L23, L24, L26, L28 }\end{array}$ & 4000 /heure \\
\hline 2 & Échangeur - Sous région & L19, L10, L27, L24, L26, L5 & $2000 /$ heure \\
\hline 3 & Sous-Région - RP Ngaba & L19, L10, L24, L27 & $2000 /$ heure \\
\hline 4 & RP Ngaba - Cité verte (CV) & L9, L14 & $2000 /$ heure \\
\hline 5 & RP Ngaba - Campus & L10, L19, L24, L27 & $1000 /$ heure \\
\hline 6 & Triangle - Campus & L14, L9 & $2000 /$ heure \\
\hline $7 \mathrm{~A}$ & UPN - Cité Verte & L21, L14, L9 & $2000 /$ heure \\
\hline $7 \mathrm{~B}$ & Cité Verte - Mitendi & L21 & 2 000/heure \\
\hline $8 \mathrm{~A}$ & Kapela - RP Bongolo & L19 & $1000 /$ heure \\
\hline $8 \mathrm{~B}$ & RP Bongolo - Cohydro & L19 & $1000 /$ heure \\
\hline 9 & RP Bongolo - RP Victoire & L11, L12 & $1000 /$ heure \\
\hline 10 & UPN - Meteo & L4, L16 & $2000 /$ heure \\
\hline 11 & Météo - DGC & L4 & $1000 /$ heure \\
\hline 12 & Mbudi - Kintambo & L17, L13 & $2000 /$ heure \\
\hline 13 & Kintambo - Socimat & L4, L13 & $2000 /$ heure \\
\hline 14 & Kintambo - Moulaert & L17, L16 & $1000 /$ heure \\
\hline 15 & Socimat - RP Mandela & L4, L6, L13 & 4000 /heure \\
\hline 16 & UPC - RP Mandela & L3, L6, L7, L11, L12, L22, L20 & 3000 /heure \\
\hline 17 & RP Mandela - F. Publique & L7, L11, L22 & $2000 /$ heure \\
\hline 18 & RP Mandela - Regideso & L2, L3, L4, L6, L12, L13 & 4000 \\
\hline 19 & $\begin{array}{lll}\text { Regideso } & - \text { Hop. } & \text { Gen. } \\
\text { Kinshasa } & & \end{array}$ & L13, L20 & 1000) /heure \\
\hline 20 & Regideso - Central Station & L4, L3, L6, L12 & $4000)$ /heure \\
\hline 21 & Échangeur - Quartier 1 & $\begin{array}{l}\text { L1, L2, L7, L8, L10, L18, L22, L23, } \\
\text { L28 }\end{array}$ & 4000 /heure \\
\hline 22 & Quartier 1 - Kingasani & L1, L7, L8, L15, L27 & 4000 /heure \\
\hline 23 & Quartier 1 - Kimbanseke & L10, L18, L28 & $1000 /$ heure \\
\hline 24 & Moulaert - UPC & L3, L6, L20 & $2000 /$ heure \\
\hline 25 & Matete - Central Station & L2 & 2000 /heure \\
\hline 26 & Cohydro - Zando & L26, L24, L23 & $1000 /$ heure \\
\hline 27 & Cohydro - Commerce & L1 & $1000 /$ heure \\
\hline 28 & Cohydro - Central Station & L12B & 1000 /heure \\
\hline 29 & Ngiri-ngiri - RP Huileries & L3B & (000/heure \\
\hline 30 & Kintambo - Meteo & L16 & 1000 /heure \\
\hline 31 & UPC - Huileries & L20 & 4000 /heure \\
\hline 32 & Huileries - Regideso & L3B, L5, L12A, L20 & $2000 /$ heure \\
\hline 33 & Kinkole - Kingasani & L15 & 2000 /heure \\
\hline 34 & UPC - RP triomphal & L7,L11 & 3000 /heure \\
\hline 35 & Cohydro - RP triomphal & L7, L5 & $3000 /$ heure \\
\hline 36 & Mbudi - DGC - Kintambo & L13 & $1000 /$ heure \\
\hline 37 & $\begin{array}{lll}\text { Lemba } & \text { terminus } & - \\
\text { Echangeur } & & \end{array}$ & L5 & $1000 /$ heure \\
\hline 38 & Bandal Tshibangu - Socimat & L6 & 1000 /heure \\
\hline 39 & $\begin{array}{l}\text { RP Victoire - Gambela } \\
\text { Station }\end{array}$ & L28, L18, L8 & 1000) /heure \\
\hline 40 & $\begin{array}{lll}\text { NgiriNgiri } & - & \text { Gambela } \\
\text { Station } & & \\
\end{array}$ & L17, L3, L16 & 1000 /heure \\
\hline 41 & Selembao - Moulaert & L20 & $1000 /$ heure \\
\hline 42 & RP Victoire - RP Triomphal & L12, L28, L8, L11 & $3000 /$ heure \\
\hline 43 & Petro Congo - Quartier 1 & L23, L22 & 1000 /heure \\
\hline
\end{tabular}

Moreover, let us consider flows of $\mathrm{k}$ distinct types of products between sources and destinations. On our network, the flow of k-type product taking the road $\mathrm{i}$ (arc or edge i) is noted $x_{i . j}^{(k)}$ where $\mathrm{j}$ represents all buses lines operating on $\mathrm{i}$; and there are 32 buses lines and 43 roads. Thus, the multiflow $\mathrm{Zi}$ on road $\mathrm{i}$ is 
Problem of Multiflow with Application in the Road Transportation Network Exploited by Transco Company in Kinshasa City

$$
\mathrm{Z}_{\mathrm{i}}=\sum_{j=1}^{i=32} x_{i j}^{i=43}, \quad k=1,2
$$

To calculate the multiflow $\mathrm{Z}$ on the entire network, we will use all roads, all types of products and all buses lines. Thus, we obtain $\mathrm{Z}$ using the following formula:

$$
\mathrm{Z}=\sum_{k=1}^{k=2} \sum_{i=1}^{i=43} \sum_{j=1}^{j=32} x_{i j}^{(k)}
$$

Eq. (5) implies $x_{i . j}^{(k)}=0$ if the product $\mathrm{k}$ takes not the road $\mathrm{i}$ or if the product $\mathrm{k}$ is not affected to the line $\mathrm{Lj}$. It is always solved under the following constraints [9]:

$\sum_{k=1}^{2} x_{i . j}^{(k)} \leq C_{i . j},=1, \ldots, 43$ et $\mathrm{j}=1, \ldots 32$

$\sum_{k=1}^{2} x_{i . j}^{(k)}-\sum_{k=1}^{2} x_{j i}^{(k)}=0, \forall i=2, \ldots, \mathrm{n}-1$

$\sum_{k=1}^{2} x_{i . j}^{(k)}=\sum_{k=1}^{2} x_{j . i}^{(k)}, \quad \forall i=\operatorname{source}, \forall j=$ destination $\quad(6 \mathrm{c})$

$x_{i . j}^{(k)} \in \boldsymbol{N} \quad(6 \mathrm{~d})$

Assume $x(\mathrm{i} . \mathrm{jk})$ the $\mathrm{k}$-type flow from $\mathrm{Lj}$ line moving on the road $\mathrm{i}(1 \leq \mathrm{k} \leq 2 ; \mathrm{k}$ : integer). Noting by $\mathrm{Z} 1$ and $\mathrm{Z} 2$ respectively the total flow of type 1 and the total flow of type 2 in the network, we obtain the following fuzzy linear program

$$
\begin{aligned}
& \max Z_{1}=\sum x_{i . j}^{(1)}, \quad i \in\{1,2,4,10,12,13,14,18,19,24,27,28,33\} ; \\
& j \in\{1,2,4,5,7,8,9,10,13 A, 13 B, 14,15,16,17,18,19,24,27,28\} . \\
& \operatorname{Max} Z_{2}=\sum x_{i . j}^{(2)}, \quad i \in\{16,20,38,8,28,24,21,43,1\} ; j \in\{3 A, 3 B, 6 A, 6 B, 11,12 A, 12 B, 20,22,23,26\} \text {. } \\
& \mathrm{X}_{1.1}^{(1)}+\mathrm{X}_{1.5}^{(1)}+\mathrm{X}_{1.7}^{(1)}+\mathrm{X}_{1.8}^{(1)}+\mathrm{X}_{1.18}^{(1)}+\mathrm{X}_{1.19}^{(1)}+\mathrm{X}_{1.22}^{(2)}+\mathrm{X}_{1.23}^{(2)}+\mathrm{X}_{1.24}^{(1)}+\mathrm{X}_{1.26}^{(2)}+\mathrm{X}_{1.28}^{(1)} \leq 4.000 \\
& \mathrm{X}_{2.19}^{(1)}+\mathrm{X}_{2.10}^{(1)}+\mathrm{X}_{2.27}^{(1)}+\mathrm{X}_{(12.24}^{(1.26}+\mathrm{X}_{(1)}^{(1.2)} \leq 2.000
\end{aligned}
$$

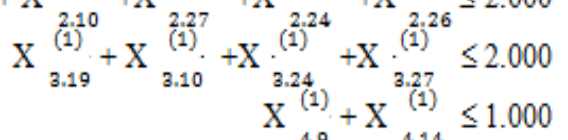

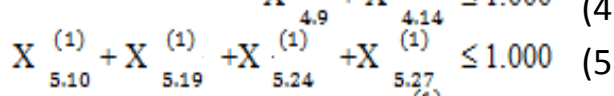

$$
\begin{aligned}
& \mathrm{X} \frac{5.27}{6.9} \leq 1.000 \\
& \mathrm{X}^{(1)}+\mathrm{X}^{(1)}+\mathrm{X}^{(1)} \mathrm{(i)}^{(1)} \leq 2.000 \quad(7) \\
& \mathrm{X}^{(2)^{(2)}}+\mathrm{X}^{(1)^{7.21}}+\mathrm{X}^{(2)} \leq 1.000 \\
& \mathrm{X}_{9,11}^{(2)}+\mathrm{X}_{9.8}^{8.11}+\mathrm{X}_{9,28}^{8.19}+\mathrm{X}_{9.12}^{\frac{8.12}{(2)}} \leq 1.000 \\
& X_{10.4}^{9.212}+X_{10.16}^{9(1)} \leq 2.000 \quad(10) \\
& \mathrm{X}_{11.4}^{(1)} \leq 1.000 \text { (11) } \\
& \mathrm{X}^{(1)}+\mathrm{X}^{\frac{11.4}{(1)}} \leq 1.000 \\
& \mathrm{X}^{(1)}+\mathrm{X}^{\frac{12.17}{(1)}}+\mathrm{X}^{\frac{112,13}{1(1)}} \leq 2.000 \\
& \begin{array}{c}
\mathrm{X}_{13.4}^{(1)}+\mathrm{X}_{13,13}^{13.13}+\mathrm{X}_{13.13^{\prime}} \leq 2.000 \text { (13) } \\
\mathrm{X}_{(14.17}^{(1)}+\mathrm{X}_{(14.6}^{14.6}+\mathrm{X}_{14.16} \leq 1.000 \text { (14) }
\end{array}
\end{aligned}
$$

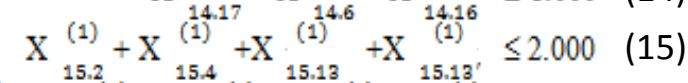

$$
\begin{aligned}
& \mathrm{X}_{16.12}{ }^{(2)}+\mathrm{X}_{16.22}{ }_{16}^{(2)}+\mathrm{X}_{16.11}^{15.2}{ }^{(2)}+\mathrm{X}_{16.3}^{15.4}+\mathrm{X}_{16.6}^{(2)}+\mathrm{X}_{16.7}^{15.13} \leq 3.000 \\
& \mathrm{X}^{(1)}+\mathrm{X}_{17,11}^{(2)} \mathrm{X}^{(2)} \leq 2.000 \quad \text { (17) }
\end{aligned}
$$

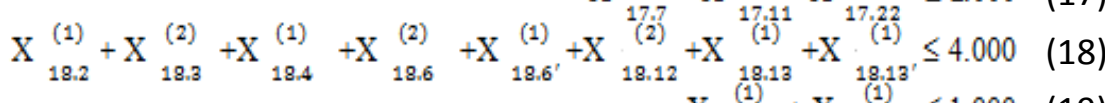

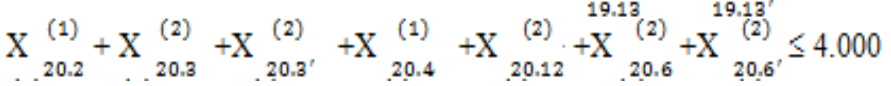




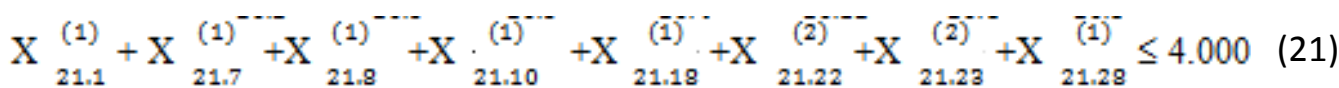

$$
\begin{aligned}
& \mathrm{X}_{22.1}^{(1)}+\mathrm{X}_{22.7}^{(1)}+\mathrm{X}_{22.8}^{(1)}+\mathrm{X}_{22.15}^{(1)}+\mathrm{X}_{22.27}^{(1)} \leq 4.000
\end{aligned}
$$

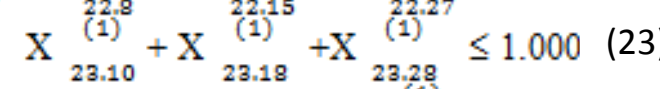

$$
\begin{aligned}
& \mathrm{X}^{(1)} \leq 2.000 \text { (24) } \\
& \mathrm{X}_{26.26}^{(1)}+\mathrm{X}_{26.24}^{(1)}+\mathrm{X}_{26.23}^{\stackrel{(25.2)}{(2)}} \leq 1.000 \\
& \mathrm{X}^{(1)} \leq 1.000 \\
& \mathrm{X} \underset{28.12^{\prime}}{27.1} \leq 1.000 \\
& \mathrm{X}{ }^{(1)}{ }^{29.12} \leq 1.000
\end{aligned}
$$

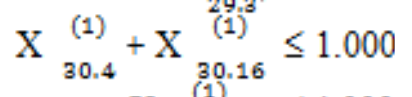

$$
\begin{aligned}
& \mathrm{X}^{\text {(1) }}+\leq 4.000
\end{aligned}
$$

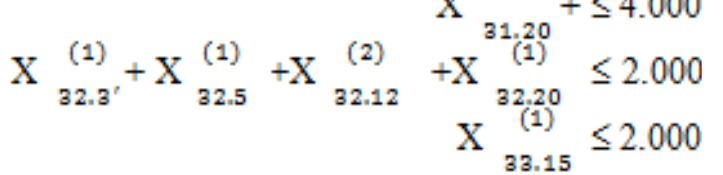

$$
\begin{aligned}
& \mathrm{X}_{34.7}^{(1)}+\mathrm{X}_{35.11}^{(2)} \leq 3.000 \\
& \mathrm{X}_{35.5}^{(1)}+\mathrm{X}_{35.7}^{(1)} \leq 3.000 \\
& \mathrm{X}_{36.13^{\prime}} \leq 1.000 \\
& \mathrm{X}_{37.5} \leq 1.000 \\
& \mathrm{X}_{38.6^{\prime}} \leq 1.000 \\
& \mathrm{X}_{39.16}^{(1)}+\mathrm{X}_{39.28}^{(1)}+\mathrm{X}_{39.8}^{(1)} \leq 1.000
\end{aligned}
$$

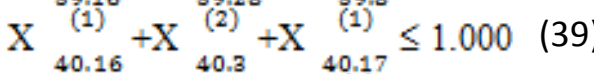

$$
\begin{aligned}
& \mathrm{X}_{41.20}^{(1)} \leq 1.000 \\
& X_{43.11}^{(2)}+X_{43.12}^{(2)} \leq 000
\end{aligned}
$$

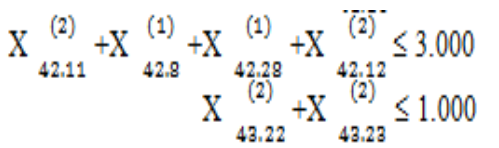

To solve linear program above, we have used a software called «LINEAR PROGRAM SOLVER » (LIPS) under Cholesky's decomposition.

\section{RESULTS AND INTERPRÉTATION}

We have found the following solution:

$\operatorname{maxZ1}=8990$

$\operatorname{maxZ2}=3117$

Thus, $(\mathrm{Z} 1, \mathrm{Z2})=(8$ 990, 3 117 $)$

- A considerable gap between the calculated multi flow (8 990, 3 117) and the experimental flow $(390,90)$, that really pass on the network. The calculated multi flow is the one that would pass if traffic is optimal on the network.

- The self propelling park $\mathrm{n}$ circulation of yhe Transco actuel is esteemed to 480 vehiles.

- Ttansco add its equipement of 11627 vehicles for realizing the maximal multiflow of its network. 


\section{CONCLUSION}

We are no doubt convinced that TRANSCO produces a service on behalf of Kinshasa people but does not cover the entire city road network. One of the essential objectives of this study was also to suggest a mathematical solution for problems of traffic jams that erode the network under study. The solution found consists in reducing the number of moving buses by requiring at the same time city transporters to buy big buses for common transportation. Personal transport will be reserved exclusively to a well controlled minority. In this paper, the calculated multi flow sets the number of buses to be reached and suggests their sharing on the whole of the network under study. Considering the importance of this to pie in the management of the city of Kinshasa, we suggest for future researchers:

1. The application of multi flow with three products (TRANSCO buses, personal buses, private buses) on the TRANCO network;

2. The application of the fuzzy multi flow on the Kinshasa city network;

The application of multi flow on the DRC road network.

\section{REFERENCES}

[1] C. Bentz. Résolution exacte et approchée de problème de multiflot entier et de multicoupe : Algorithmes et complexité. PhD thesis, Ecole polytechnique fédérale de Lausanne, Suisse, 2006.

[2] M.C. Costa. Multicoupes et multiflots entiers, Lausanne, 2007.

[3] S. DELEPLANQUE. Modélisation et Résolution de problèmes de transport à la demande et de lotsizing, thèse de doctorat, Université Blaise-Pascal-Clermont-Ferrand, Septembre 2014.

[4] J.Edmonds and R.M. Karp. Theoretical Improvements in Algorithmic Efficiency for Network Flow Problems. Journal of the Association for Computing Machinery, 9(2):248 - 264, 1972.

[5] L.R. Ford and D.R. Fulkerson. Flows in Networks, Princeton University Press, 1962.

[6] T.E. Harris and F.S. Ross. Fundamentals of a Method for Evaluating Rail Net Capacities. ( U ) RAND Corporation, Research Memorandum RM-1573, 1956.

[7] M. Karim. Multiflots, métrique et graphes h - parfaits : Les cycles impaires dans l'optimisation combinatoire. PhD thesis, Université Joseph - Grenoble 1, France, 1996.

[8] Kenababo Mpiana. Détermination du flot de coût minimum dans un réseau de transport par l'algorithme de Busacker et Gowen. Implémentation et application au réseau routier de la ville de Kinshasa. Mémoire de Licence, Université de Kinshasa, 2007 - 2008.

[9] F. Mamanya and R. Mabela. Un nouvel algorithme pour la détermination de flot maximal, International Journal of Innovation and Applied Studies, ISSN 2028-9324, Vol. 21 N³, 3 oct. 2017, pp. 492-498

[10] F. Mamanya. Etude de Multiflot dans un Réseau de Transport Routier. Cas de réseau routier de la Ville de Kinshasa, Mémoire de DEA, Université Pédagogique Nationale, 2012

[11] R. Renfrey Potts. Flows in Transportation Network. Academic Press, New York and London, 1972.

[12] http : www.transco-rdc.cd

\section{AUTHORS' BIOGRAPHY}

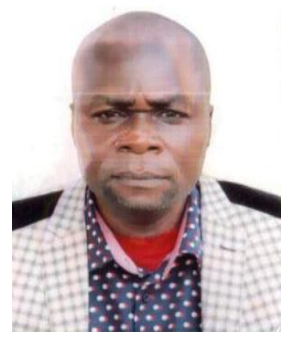

Fernand MAMANYA TAPASA, he teaches in the " Université Pédagogique Nationale. His research (fuzzy theory). His latest publications have to do with the study of multiflow they are:

A special prerequisite to the calculation of the multiflow in journal international of innovation and applied studies, 2016.

A New Algorithm for the calculation of maximal fuzzy flow, in journal international of Innovation and Applied studies, 2017.

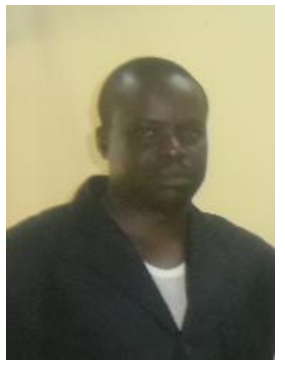

Rostin MABELA MAKENGO MATENDO, is a Professor in the Department of Mathematics and Computer Science, in the Faculty of Science, at the University of Kinshasa, Democratic Republic of the Congo.

His area of interest covers Operations Research, Applied Probability and Fuzzy Analysis of Queueing Systems. 
Problem of Multiflow with Application in the Road Transportation Network Exploited by Transco Company in Kinshasa City

Citation: F. M. TAPASA, R. M. M. MATENDO, "Problem of Multiflow with Application in the Road Transportation Network Exploited by Transco Company in Kinshasa City ", International Journal of Scientific and Innovative Mathematical Research, vol. 5, no. 6, p. 25-33, 2017., http://dx.doi.org/10.20431/2347-3142.0506003

Copyright: (C) 2017 Authors. This is an open-access article distributed under the terms of the Creative Commons Attribution License, which permits unrestricted use, distribution, and reproduction in any medium, provided the original author and source are credited. 